\title{
LAS ETAPAS DEL ITER CRIMINIS, Y SU APLICACIón PRÁCtica EN LOS TIPOS DE INJUSTO DE HOMICIDIO Y ASESINATT
}

\author{
JUAN BAUTISTA CASTRO MARADIAGA \\ Especialista en Derecho Penal y \\ Derecho Procesal Penal
}

\section{Introducción}

La idea de estudiar y realizar un análisis teórico práctico, del iter criminis, es para mi una pasión que abarca desde mi punto de vista, la más importante valoración que debe realizar un juzgador, fiscal, defensor, o bien un estudioso del derecho penal, al momento de determinar el grado de responsabilidad penal que posee un sujeto activo, en una situación fáctica específica, desde el momento en que decide exteriorizar una conducta que el ordenamiento jurídico penal considera reprochable.

Las etapas del iter criminis, representan el camino que ha de seguir o recorrer el sujeto activo, al momento de la comisión de una determinada conducta prohibida, descrita en el supuesto de hecho de la norma jurídico penal, mismo, que se encuentra normado en nuestra legislación penal, pero que presenta, en la práctica, gran dificultad de aplicación, por cuanto, resulta complicado el determinar, tomando en cuenta la psiquis del sujeto activo, hasta donde ha llegado su intención; si ésta se corresponde al resultado obtenido, mismo, que puede o no ser punible por la norma penal ad hoc, sea por que la conducta ejecutada no es típica; porque desistió o se arrepintió eficazmente, de iniciar o continuar con la ejecución del tipo de injusto; porque los medios eran inadecuados para consumar el hecho; o porque aún cuando los medios eran los idóneos, el bien jurídico protegido era inexistente o el objeto material sobre el 


\section{Revisla de Perecho}

que recae la acción estaba ausente. Estas son las razones por las que, la dirección de este trabajo está indicada, a plantear como se aplica en situaciones fácticas, lo que teóricamente se conoce como el recorrido del delito, sus dificultades, ventajas y desventajas, en cuanto a la responsabilidad penal que se corresponde a cada etapa, explicando con detenimiento, que no todo el iter criminis es punible, sino sólo aquellos actos que objetivamente representen una ofensa -puesta en peligro o lesión-, a un bien jurídico protegido, por la norma penal sustantiva, lo cual, voy a plantear mediante ejemplificaciones que parten de una base dogmática y jurídica, acerca de situaciones fácticas que ocurren a diario y que pueden o no ser sancionadas.

La casuística que será empleada, al momento de ejemplificar cada una de las etapas que componen el camino a seguir por el activo, y que conllevan a la consumación de la conducta típica, girara única y exclusivamente en torno al tipo legal de injusto base de Homicidio, y al tipo cualificado de Asesinato, mismos que tutelan el bien jurídico "Vida", y que se presentan como injustos penales de resultado, en los que se pueden apreciar todas y cada unas de las etapas en cuestión, lo cual, se apoyará en el Código Penal Vigente y el Nuevo Código Penal.

\section{Concepto de iter criminis}

El iter criminis, entendido como el camino del crimen, comprende todo el proceso psicológico de incubación del proceso delictivo, hasta la perpetración del delito, con la consideración jurídica y social, en cada etapa, de la punibilidad y peligrosidad de la actitud y del sujeto ${ }^{1}$. Es el estudio dogmático penal, de la psiquis del sujeto activo, desde el momento en que ha ideado la consumación de un determinado injusto penal, hasta que ha logrado conseguir la misma, e incluso agotarla. Si bien, dicho recorrido inicia desde los actos preparatorios internos, en materia penal y para efectos de punibilidad de la conducta, sólo son tomados en cuenta los actos preparatorios externos, que presuponen una intencionalidad exteriorizada por el sujeto activo, de ejecutar los actos que objetiva y subjetivamente le permitirían ofender un bien jurídico tutelado por la norma penal.

CABANELLAS DE TORRES, Diccionario Jurídico Elemental, ed. Eliasta, Decimosexta edición, 2003, pág. 213. 


\section{Recissa de Perecho}

El camino del delito está compuesto por las fases; Interna, que comprende la ideación, temores e incluso la decisión, que surge en la mente del sujeto activo, -determinadas por condiciones exteriores-, de cometer un injusto penal en específico, lo cual, no implica un modo de comportamiento exteriorizado del autor, capaz de ofender un bien jurídico protegido, púes al encontrarse únicamente dentro de la psiquis del sujeto activo, no son de relevante importancia para el derecho penal, por cuanto, rige el principio de cogitationis poenam nemo patitur -Los pensamientos no son punibles-; Externa, que presupone la voluntad delictiva exteriorizada por el activo, de realizar una conducta prohibida, capaz de transformarse en realidad peligrosa ${ }^{2}$; Ejecutiva, la cual está conformada por el inicio y culminación de los actos necesarios para consumar una conducta, descrita en el supuesto fáctico determinado por la norma penal sustantiva -tentativa simple, acabada, la consumación y el agotamiento-.

Estas fases de realización del delito, específicamente la del tipo tentativa -acabada e inacabada- y el consumado, si bien no obedecen necesariamente a la misma naturaleza, subjetivamente presentan similitudes relevantes que serán abordadas con posterioridad, partiendo del hecho de que los primeros son formas imperfectas de la consumación del injusto, las cuales resultan punibles, desde los actos preparatorios externos, que constituyen una exteriorización de la voluntad del sujeto activo de poner en peligro real y objetivo a un bien jurídico protegido y sobre los que a continuación centraré mi atención.

\section{Actos preparatorios}

Los actos preparatorios, presuponen una serie de conductas materializadas o no, en el mundo exterior y realizadas a priori de los actos ejecutivos, que crean una posibilidad real de puesta en peligro de un bien jurídico protegido, pues persiguen a posteriori, el dar principio a los actos necesarios para consumar la parte objetiva y subjetiva del tipo de injusto, circunstancia que no siempre podrá ser apreciada en un determinado cuadro fáctico.

$\mathrm{Al}$ respecto, es claro que, no todos los actos ideados e incluso decididos a realizar, son punibles, -actos preparatorios internos-, sino sólo aquellos,

2 COBO DEL ROSAL / VIVES ANTON, Derecho Penal Parte General, Segunda Edición, Tirant lo Blanch, Valencia, 1987, pág.493. 
que objetiva y subjetivamente representen una ofensa a un bien jurídico tutelado por la norma penal sustantiva, -actos preparatorios externos-. Ahora que puede darse el caso en el que, quien ha ideado la comisión de un determinado injusto penal, decide contárselo a un tercero, sea verbalmente, por escrito o por cualquier medio, -revelación de la intención delictiva-, de lo que pueden valorarse dos circunstancias; si el sujeto activo que cuenta su intención delictiva, no llega a ejecutarla por medios materiales adecuados, tal circunstancia no determina responsabilidad penal alguna, púes, constituye una simple declaración respecto del propósito de cometer algún injusto penal, esto fuera de los casos en que dicha declaración constituya con apego a la norma penal sustantiva, un delito instantáneo. En caso de que el sujeto activo que ha declarado su intención delictiva a otro sujeto, ejecute la parte objetiva del tipo, logrando consumar el hecho, permite establecer responsabilidad penal, incluso para aquel que pudiendo evitarlo o denunciarlo, adoptó una conducta omisiva.

\section{Los actos preparatorios pueden ser}

\subsection{Internos:}

Desde mi punto de vista, estos son actos que no tienen vida en el mundo exterior, por cuanto, se encuentran en la psiquis del sujeto activo al momento en que este planea mentalmente la ejecución de una determinada conducta prohibida, lo cual, no supone una puesta en peligro a un bien jurídico tutelado por la norma penal sustantiva. Así pues, estos actos internos: ideación -planificación mental de la realización de un determinado injusto penal-, deliberación - análisis mental que realiza el sujeto activo, respecto de las posibilidades de ejecutar certeramente el injusto penal ideado- y la resolución - que presupone la voluntad consciente de parte del sujeto activo, de iniciar la ejecución de un determinado injusto penal-, resultan ser penalmente impunes, por cuanto, estos aún no han sido exteriorizados por el agente y no representan una ofensa -puesta en peligro- a un bien jurídico, pues en caso contrario, estaríamos en presencia de un derecho penal de autor, o modernamente conocido como derecho penal del enemigo, en el que se castiga a los ciudadanos, por su apariencia física e incluso por sus pensamientos. 


\subsection{Externos:}

Estos actos externos, presuponen la exteriorización de una voluntad delictiva que trasciende e involucra a otros sujetos, en la posible ejecución de un determinado injusto penal, lo cual, denota una especial puesta en peligro al bien jurídico protegido, siendo esta la principal razón para su punición ${ }^{3}$. Ahora que, para que determinadas conductas puedan ser sancionadas como actos preparatorios externos, deben estar contenidos expresamente en la norma penal sustantiva, regulación que efectivamente realiza nuestra legislación, al tipificar los siguientes actos externos:

\subsubsection{Conspiración:}

El Código Penal vigente ${ }^{4}$, en adelante Pn, establece cuales son los actos preparatorios externos que resultan relevantes para el derecho penal, siendo estos; la conspiración -conjuración o confabulación de varias personas contra alguno, con el objeto de perderle o causarle daño ${ }^{5-}$ y la proposición -iniciativa que una persona hace llegar a otra, con objeto de obtener su concurso ${ }^{6}$ - para cometer un delito. Así pues, la norma penal sustantiva plantea que:

"La conspiración existe cuando dos o más personas se conciertan para cometer un delito y resuelven ejecutarlo,"

Regulación que expresamente requiere, para la punibilidad de la conducta, que esta sea ejecutada por una pluralidad de sujetos activos, quienes deben haber resuelto conjuntamente, el ejecutar un determinado un injusto penal7 .

Si bien la conspiración, en un principio supondría una asociación para delinquir, es preciso aclarar, que aunque en ambas conductas se pretende la tutela de bienes jurídicos protegidos que han sido puestos en peligro

$3 \quad$ MIR PUIG, Derecho Penal Parte General, sexta edición, Barcelona, 2002, pág. 334.

4 Ver Art. 7 del Código Penal de la República de Nicaragua.

5 CABANELLAS DE TORRES, Diccionario Jurídico Elemental, ed. Eliasta, Decimosexta edición, 2003, pág. 88.

6 CABANELLAS DE TORRES, Diccionario Jurídico Elemental, ed. Eliasta, Decimosexta edición, 2003, pág. 325.

7 De ahí que un sector de la doctrina Española, considere a la conspiración como una forma de coautoria anticipada, cuyas consecuencias fundamentales son: a) Solo pueden ser sujetos activos de la conspiración, quienes reunan las condiciones necesarias para ser autores del delito proyectado; b) La decisión de ejecutar la conducta prohibida debe constituir una decision firme de ser coautor de un delito concreto. MIR PUIG, Derecho Penal Parte General, sexta edición, Barcelona, 2002, pág. 335 y 336. 
por actos externos, la asociación para delinquir exige una permanencia en el tiempo, de tal manera que, mientras los conspiradores conjuntamente planean la comisión de un injusto penal determinado, los asociados para delinquir, se dedican permanentemente a la consumación de conductas prohibidas.

El Nuevo Código Penal, en adelante NCP, también regula la conspiración, como un acto preparatorio externo, que merece ser penado, estableciendo que esta tiene lugar cuando dos o más sujetos activos se concierten para la ejecución de un injusto penal y resuelven llevarlo acabo ${ }^{8}$, definición que no varía en lo absoluto, en relación con la normativa penal vigente y sobre la que el suscrito ya se ha referido. La tipificación de este acto preparatorio en la práctica se observa con facilidad;

Ejemplo: A, B y C se reúnen en horas de la mañana, para cometer al siguiente día, el tipo legal de injusto de Asesinato, en perjuicio de D, planificando el lugar, la hora y los medios necesarios para darle muerte mediante mutilaciones.

\subsubsection{Proposición:}

Respecto de este acto preparatorio externo, el Código Penal vigente, establece la configuración de esta conducta punible de la siguiente manera:

"La proposición se verifica cuando él o los que han resuelto cometer un delito incitan para su ejecución a otra u otras personas ${ }^{9}{ }^{. *}$.

Definición de la que se desprende que en primer lugar, pueden existir, uno o varios sujetos activos que hayan ideado y decidido realizar un determinado injusto penal y que basados en esa decisión delictiva, inviten a otro $\mathrm{u}$ otros sujetos activos, a realizar el hecho punible, por lo que, en dicho acto externo, se pena la puesta en peligro real de un bien jurídico tutelado por la norma penal sustantiva.

Así mismo, dicho acto preparatorio externo, se amplía en el arto. 496 Pn. pues establece como conducta punible, no sólo la de el que proponga a otro

$8 \quad$ Ver Art. 31 párrafo primero, del Nuevo Código Penal de la República de Nicaragua.

9 Ver Art. 7 párrafo segundo del Código Penal de la República de Nicaragua. 
la comisión de un delito, sino la de aquel que aceptare la propuesta ${ }^{10}$. En este sentido, si el segundo sujeto activo acepta la propuesta ilícita, pasarán a ejecutar el hecho punible, como coautores, siendo criterio del suscrito, que como sostiene parte de la doctrina, no puede haber conspiración entre ellos, por cuanto no han resuelto ejecutar la conducta prohibida conjuntamente, sino, que quien propone la ejecución conjunta de la misma, es quien ha resuelto primeramente ejecutarla y quien en caso de que él segundo sujeto activo no acepte la propuesta delictiva, responderá por el acto de proponer la comisión de un injusto.

Lo anterior, se ampara en la normativa penal vigente que establece la eximente de responsabilidad penal, para aquellos sujetos activos, que antes de haber comenzado la ejecución de los actos conspirados o que han propuesto ejecutar, desistan voluntariamente de realizar los mismos ${ }^{11}$, lo que implica que, si los sujetos activos planearon la ejecución del asesinato de un sujeto pasivo determinado, a una hora determinada, y no se hacen presentes en el lugar acordado, a ejecutar la conducta prohibida, tal acto de conspiración es impune, o bien que si el que ha resuelto ejecutar el hecho punible y proponérselo a otro sujeto activo, no realiza tal acto, su conducta será evidentemente impune, por cuanto, en ambos casos, el bien jurídico protegido jamás fue expuesto.

En lo que hace al NCP, la proposición también se encuentra regulada como un acto externo, reprochable por el ordenamiento jurídico penal, plasmando que:

“Existe proposición cuando el que ha resuelto cometer un delito invita a otra $u$ otras personas a ejecutarlo. ${ }^{.12}$

Mandato que no presenta grandes diferencias, respecto de la definición brindada por el Pn. en la que el verbo empleado incitar, es el que daba principio a la conducta prohibida, a diferencia del NCP, en el que se emplea el verbo, invitar, existiendo en ambas conductas, el mismo problema de aplicabilidad práctica, pues la forma en que se redactaron dichos artículos, sugiere que el proponente que ha decidido realizar el delito, invita a otro

10 Arto. $496 \mathrm{Pn} "$ El que proponga a otro la comisión de un delito, incurrirá en arresto de un a tres años. En la misma sanción incurrirá el que aceptare la propuesta. Si a la propuesta se acompañare la entrega de valores, la sanción se aumentará hasta en una mitad"

11 Art. 7 Pn. "...Exime de toda pena el desistimiento de la conspiración o proposición para cometer un delito, siempre que se haga antes de haber comenzado su ejecución".

12 Ver Art. 31 párrafo segundo, del Nuevo Código Penal de la República de Nicaragua. 
$\mathrm{u}$ otros para que sean estos los que lo ejecuten y no para que participen en la ejecución, lo cual, constituiría una forma punición de la tentativa de inducción, en la que un sujeto activo -inductor-, hace nacer y ejecutar en otro -inducido-, la idea de consumar un determinado injusto penal, en el que el inductor no participa.

En cuanto a la aplicación fáctica de este acto preparatorio externo, cito el siguiente ejemplo: A, quien ya ha tomado la decisión de Asesinar a B, planificando la hora, lugar y fecha de comisión, propone a sus amigos $\mathrm{C}$ y $\mathrm{D}$, que sean ellos, quienes lo ejecuten.

\subsubsection{Provocación:}

En la legislación penal vigente, no se encuentra regulada la provocación -incitación, exitación a ejecutar algo ${ }^{13}$, misma que consiste en una incitación hecha por un sujeto activo, quien no realiza directamente el tipo objetivo de la conducta prohibida descrita en el supuesto de hecho de la norma jurídico penal, sino que hace que otros sujetos activos la ejecuten por él, es decir que, él provocador induce a otros, por diferentes medios, a realizar la conducta prohibida, por la norma penal sustantiva.

Esta figura se encuentra regulada en el NCP, plasmándose que:

"La provocación existe cuando directamente o indirectamente, pero por medios adecuados a su eficacia, se incita a la realización de un delito ${ }^{14}$.

De este concepto legal, se desprende que, este acto preparatorio externo puede ejecutarse directamente, de una persona a otra, o bien a través de medios televisivos, radiales, escritos, entre otros -indirectamente-, con el animus, de que la persona o personas a quien se dirige, ejecuten la conducta descrita en el tipo, dado que, el provocador no tiene intención de ejecutar directa o materialmente el injusto penal determinado, al que induce realizar.

Cabe mencionar que si bien, la provocación es una forma de inducción, mientras en la primera se protege la puesta en peligro de un bien jurídico protegido determinado, sancionando al provocador, en la segunda setutela

13 CABANELlAS DE TORRES, Diccionario Jurídico Elemental, ed. Eliasta, Decimosexta edición, 2003, pág. 327.

14 Ver Art. 32 párrafo primero, del Nuevo Código Penal de la República de Nicaragua. 


\section{Revisla de Derecho}

la lesión que ha sufrido un bien jurídico determinado, como resultado de la inducción.

Así pues, existe provocación en la práctica cuando; A, locutor de la radio "La Revoltosa", en su programa de noticias matutinas, incita a la población a privar de la vida a B, quien un día antes, asesino salvajemente a la menor C, encontrándose dicho sujeto activo tranquilamente en su casa de habitación que cita..., datos que son suministrados por el provocador a los pobladores. De aquí se desprende que si la población decide ejecutar la conducta prohibida descrita en el tipo de injusto de Homicidio, A, será inductor de dicho injusto, recibiendo la misma pena que el autor y si nadie secunda su idea, será simplemente un provocador del injusto en cuestión.

\subsubsection{Apología:}

La apología del delito -elogió, solidaridad pública o glorificación de un hecho delictivo o de su autor a causa de é ${ }^{15}$-, se encuentra regulada en la parte especial del Pn. "Delitos Contra el Orden Público", estableciendo como punibles aquellas conductas ejecutadas por un sujeto activo y que se dirijan no sólo a la incitación a la comisión de un injusto penal determinado, sino también aquellas dirigidas a la incitación de acometer un genero de tipos legales de injusto, plasmándose también que, se considera apología el incumplimiento de una Ley, o bien el hacer mofa de sus disposiciones ${ }^{16}$. Estos conceptos otorgados por nuestra legislación penal vigente, no son claros en determinar en que consiste directamente la apología del delito, misma que básicamente se refiere a la exposición directa, ante un grupo de personas, de ideas que engrandezcan una conducta típica o bien que halaguen al sujeto activo de la misma.

El NCP regula la apología del delito, como una forma o clase de provocación, y nos establece expresamente que esta conducta será típica cuando el sujeto activo, ante una concurrencia de ciudadanos, ensalce el crimen o enaltezcan a su autor y partícipes de un injusto penal que ya acaeció $^{17}$, exigiéndose que el sujeto activo realice la conducta directamente,

15 CABANELLAS DE TORRES, Diccionario Jurídico Elemental, ed. Eliasta, Decimosexta edición, 2003, pág. 36.

16 Art. 495 Pn.- "El que de manera pública y directa haga la apología de un delito o género de delitos, incurrirá en arresto de uno a seis meses y en multa de veinte a quinientos córdobas, y en la misma pena incurrirá el que de manera pública incite al incumplimiento de una ley o la denigre en cualquier forma o haga mofa de sus disposiciones....

17 Ver Art. 32 párrafo segundo, del Nuevo Código Penal de la República de Nicaragua. 
ante un conglomerado de personas -no por medios audiovisuales, radiales $u$ otros- y con el único objetivo de enaltecer el crimen o a sus autores, incluyendo a los partícipes, lo que es un elemento novedoso en la definición que se otorga respecto de este injusto penal, y que no se encuentra contemplado en la legislación penal vigente.

Debe dejarse claro, que la norma penal no considera delictiva, el libre ejercicio constitucional de la libertad de pensamiento, de expresión, así como el derecho a la información, siempre que no vulneren derechos constitucionales de terceros, ni contravengan a la norma fundamental o leyes especiales. ${ }^{18}$

La aplicación fáctica de la apología se observa fácilmente en el siguiente Ejemplo: A, quien al encontrarse dirigiendo una marcha universitaria, misma que es reprimida por las tropas especiales de la Policía Nacional, le expresa a la multitud que deben recordar el asesinato atroz, cometido por B, C y D, en contra de E, oficial de policía, hecho acaecido hace una semana y cuya conducta ejecutada por los sujetos activos, merece admiración y debe servir de ilustración.

\subsubsection{Diferencia entre actos preparatorios y actos ejecutivos.}

Antes de pasar al análisis de los actos de ejecución, es preciso mencionar que estos, son teóricamente distintos de los actos preparatorios, pero que en la aplicación práctica de las conceptualizaciones, resulta sumamente complicado el diferenciar cuando uno de los actos exteriorizados por un sujeto activo determinado, ha dejado de ser preparatorio y se convierte en ejecutivo.

$\mathrm{Al}$ respecto existen diversas teorías que tratan de dar respuesta a esta incógnita, de las que sobresale la teoría intermedia o mixta, misma que combina dos aspectos de la acción típica (subjetivos y objetivos); el plan del sujeto activo - visualizaciones respecto de el desencadenamiento de la acción típica- y si de acuerdo a estas visualizaciones, la conducta exteriorizada por el autor, se encuentra estrechamente ligada, a la acción descrita en la parte objetiva del tipo, no existiendo elementos intermedios que impidan el poner en actividad inmediata su ejecución, teoría que

18 Ver Arts. 29, 30 y 66 de la Constitución Política de la República de Nicaragua y Art. 32, 2 del Nuevo Código Penal de la República de Nicaragua. 
según el maestro Muñoz Conde, presenta el problema de subjetivizar un criterio que en la ley es objetivo. ${ }^{19}$

De dicha teoría se desprende que la principal diferencia entre ambos actos, radica en el comienzo de la ejecución de la conducta típica, en la que a ciencia cierta, sólo el sujeto activo que ejecuta la conducta prohibida, conoce en que fase del delito se encuentra su intención exteriorizada, púes por ejemplo, el hecho de comprar un arma, puede ser un acto preparatorio del injusto penal de homicidio, y se convierte en acto ejecutivo, cuando emplea dicha arma con el propósito consciente y voluntario de obtener el resultado lesivo al bien jurídico vida, razón por la cual, para establecer una diferencia fáctica, debe atenderse no solo a la constitución de cada tipo de injusto en especifico, sino también de las circunstancias que acompañan su realización.

\section{Formas imperfectas de la consumación del delito.}

Se les conoce con este nombre, a las etapas del iter criminis, que parten de los actos ejecutivos que han sido exteriorizados por el sujeto activo, al momento en que se propone consumar la conducta prohibida, descrita en el supuesto de hecho de la norma jurídico penal, mismos que por su propia naturaleza no pueden llegar hasta la culminación de la parte objetiva del tipo determinado, quedando interrumpidas en cualquiera de sus etapas de ejecución. Dichas formas imperfectas, serán ejemplificadas con situaciones fácticas típicas de los injustos de Homicidio y Asesinato, los cuales al ser delitos de resultado, permiten la fácil ilustración de las mismas.

\subsection{Tentativa inacabada:}

La tentativa inacabada, se define como el actuar activo u omisivo, voluntario y consciente, de dar principio a la ejecución de la conducta prohibida, descrita en el supuesto de hecho de la norma jurídico penal, sin lograr ejecutar todos los actos de la parte objetiva del tipo, que le permitan consumar en tipo legal de injusto, debido a razones ajenas a la voluntad del agente y por ende, lejos de los supuestos de evitación voluntaria de la consumación del injusto penal -Desistimiento voluntario

19 MUÑOZ CONDE,/ GARCÍA ARÁN, Derecho Penal Parte General, 3ra. ed. Valencia, España, Tirant lo Blanch, 1998, pág. 465. 
de la consumación del delito-20. De aquí se desprende un elemento de relevante importancia y sobre el que en la doctrina hay mucha discusión, al punto de que actualmente no existe acuerdo, el comienzo de la ejecución del injusto penal.

$\mathrm{Al}$ respecto se han planteado diversas teorías que pretenden distinguir, con la mayor precisión posible, los actos ejecutivos, de los simplemente preparatorios, entre ellas tenemos; teoría objetivo formal - plantea que el punto de partida del comienzo de la ejecución de la parte objetiva del tipo, está constituido por el desarrollo de la conducta descrita por el verbo rector, empleado en el supuesto de hecho de la norma jurídico penal.-; teorías objetivo material - consideran que para determinar el comienzo de la acción descrita en el supuesto de hecho de la norma penal sustantiva, debe acudirse a criterios materiales, que permitan delimitar objetivamente el inicio del campo previo a la ejecución, tales como, la unidad natural de acción-; ${ }^{21}$-; teorías Objetivas - hay tentativa, cuando se inicia la acción típica, y ésta se interrumpe por causas independientes a la voluntad del agente ${ }^{22}$; teorías subjetivas - se basan en un derecho penal de autor, en el que el comienzo de la ejecución o tentativa inacabada, se da a través de actos que para el sujeto activo configuren la fase decisiva de su plan, es decir, la existencia en el sujeto activo, de la voluntad y consciencia de realizar la parte objetiva del tipo de injusto ${ }^{23}$; entre otras.

Sin embargo, considero que, la teoría que mejor explica el concepto de comienzo de la ejecución, es la teoría subjetivo-objetiva,

que entiende que se ha comenzado a ejecutar el injusto penal, cuando el sujeto activo realiza una serie de actos, que según su plan de acción, implican directamente la ejecución de la conducta prohibida ${ }^{24}$.

20 Bacigalupo considera que la tentativa inacabada se da cuando según el plan del activo, el resultado debe alcanzarce por varios hechos sucesivos, y en el momento en que se la considera, restan todavia por cumplir otros actos para que se produzca el resultado. BACIGALUPO, Lineamientos de la Teoría del Delito, Buenos Aires, Depalma, 1974, pág. 111.

21 MIR PUIG, Derecho Penal Parte General, sexta edición, Barcelona, 2002, pág. 339.

22 QUIROS PIRÉZ, Manual de Derecho Penal, Editorial Félix Varela, San Miguel, El Mazón y Basarrate, El Vedado, Ciudad de la Habana, pág. 77.

23 CASTILlo GONZÁLEZ, Tentativa y Desistimiento Voluntario, San José Costa Rica, Editorial Jurídica Continental, 2003, pág. 31.

24 BACIGALUPO, Lineamientos de la Teoría del Delito, Buenos Aires, Depalma, 1974, pág. 106. 
Esta figura ejecutiva, se encuentra regulada en el Pn, plasmándose que:

"Haytentativa,cuandoelculpable daprincipiodirectamentealaejecución del delito por hechos exteriores y no prosigue en ella, por cualquier causa o accidente que no sea su propio voluntario desistimiento ${ }^{25}$ "",

Definición en la que se observa la inclusión de elementos esenciales como los son; a) El requisito subjetivo de la tentativa, pues si bien, en esta no se realiza toda la parte objetiva del tipo de injusto, si concurre en toda su plenitud la parte subjetiva, misma, que en este estadio de la ejecución no resulta ser idéntica a la del delito consumado, pues como afirma el maestro Mir Puig, el dolo consiste en la realización de solo parte de los actos necesarios para consumar el injusto penal determinado y no de todos los actos requeridos para que este se consume ${ }^{26}$.

b) El comienzo de la ejecución, -exteriorización de actos ejecutivos incompletos, que persiguen la consumación del injusto y que por ende, van más allá de la fase preparatoria-; y c) El no perfeccionamiento del tipo de injusto, por razones ajenas a la voluntad del agente -no se continúa con la ejecución de los actos, por causas externas a la voluntad del sujeto activo-. En este sentido, se hace claro que, la tentativa lleva implícito el fracaso del plan delictivo del agente, debido a la interferencia de alguna circunstancia externa, que lo obliga a no continuar los actos encaminados a la consumación del hecho punible.

De la definición brindada por el Pn se desprende, que puede darse el caso, en que el sujeto activo que da principio a la ejecución de los actos punibles, decida voluntariamente no continuar con los mismos, lo cual, se conoce como desistimiento voluntario de la consumación del injusto penal, mismo, que como bien plasma la norma penal sustantiva, sólo puede darse en una tentativa inacabada y hasta antes de haber realizado todos los actos que tienden a lograr la consumación del delito, lo cual, abordaré con posterioridad.

Por su parte el NCP, establece la punibilidad del delito consumado, y de las formas imperfectas de ejecución de la conducta prohibida, plasmando desde un punto de vista objetivo, que para el caso de las faltas penales, que

25 Ver Art. 6, párrafo segundo del Código Penal de la República de Nicaragua.

26 MIR PUIG, Derecho Penal Parte General, sexta edición, Barcelona, 2002, pág. 345. 
ofendan los bienes jurídicos protegidos, integridad física y patrimonio, solo serán punibles cuando se haya consumado la conducta típica ${ }^{27}$.

En este cuerpo de leyes, la tentativa inacabada, se encuentra tipificada y definida de la siguiente manera:

"Hay tentativa cuando el sujeto, con la voluntad de realizar un delito, da principio a la ejecución del mismo directamente por hechos exteriores, pero solo ejecuta parte de los actos que objetivamente deberían producir la consumación, por cualquier causa que no sea el propio y voluntario desistimiento $^{28}{ }^{*}$.

Concepto que no presenta diferencias relevantes, respecto de la definición que realiza el Pn, pues el cambio más notorio lo constituye, el hecho de que el NCP hace referencia al inicio de la conducta, que ésta será ejecutada por el sujeto activo y no como establece el Código Penal vigente, que se refiere al culpable, lo que desde mi punto de vista, lesiona el principio constitucional y procesal de la presunción de inocencia ${ }^{29}$, propio de un sistema inquisitivo, del que el NCP, demuestra ser totalmente distante.

Ejemplo de tentativa inacabada o simple tentativa: A, quien se ha propuesto matar a B, saca y apunta con un arma artesanal a éste, con el animus necandi de darle muerte, lo cual no se produce porque $\mathrm{B}$, en ese instante toma un taxi y se retira del lugar totalmente ileso.

Lo más importante a destacar en este acto de ejecución, consiste en que el actuar del sujeto activo, al dar principio a la ejecución de actos externos, que pretenden directamente la consumación de un determinado injusto penal, ha realizado toda la parte subjetiva del tipo, el cual, en la tentativa es evidentemente doloso, no ejecutando todos los actos necesarios para consumar la parte objetiva del tipo legal de injusto, por razones ajenas a su voluntad.

27 Art. 27 del NCP establece que: "Son punibles el delito consumado, el delito frustrado y la tentativa de delito. Las faltas, excepto aquellas contra las personas y el patrimonio, solo se castigaran cuando hayan sido consumadas".

28 Ver Art. 28, acapite c), del Nuevo Código Penal de la República de Nicaragua.

29 Ver Art. 34 ordinal 1, de la Constitución Politica de la República de Nicaragua. 


\subsection{Tentativa acabada:}

La tentativa acabada o frustración se define como aquella conducta exteriorizada por el sujeto activo, que presupone la ejecución de todos los actos objetivamente necesarios, para que pueda obtenerse el resultado lesivo al bien jurídico protegido por la norma penal sustantiva, el cual no se produce por razones ajenas a la voluntad del agente, y por ende, lejos de los supuestos de evitación voluntaria de la consumación del injusto penal -arrepentimiento eficaz que impide la consumación ${ }^{30}{ }_{-}$.

$\mathrm{Al}$ respecto el Pn, establece que:

"Hay delito frustrado cuando el culpable, a pesar de haber hecho cuanto estaba de su parte para consumarlo, no logra su propósito por causas independientes de su voluntad ${ }^{3{ }^{1}}$.

Definición de la que se desprenden los siguientes elementos; a) El elemento subjetivo del tipo, mismo que en la tentativa y según la descripción del tipo siempre será a título de dolo, pues se requiere que el sujeto activo quiera los actos que objetivamente realiza, o al menos que acepte la probabilidad de ofender, a posteriori, con su actuar voluntario y consciente, un bien jurídico protegido por la norma penal sustantiva ${ }^{32}$.

Cabe mencionar, que en este estadio de la fase ejecutiva, el dolo empleado por el agente, a diferencia de la tentativa inacabada, si resulta ser idéntico al dolo del injusto penal consumado, por cuanto, el sujeto activo ya ha exteriorizado todos los actos que objetivamente le permitirían lesionar al bien jurídico, lesión, que no se hace efectiva por causas externas al agente, es decir, que al haber sido, la intencionalidad delictiva y exteriorizada del sujeto activo, absolutamente terminada, esta fase, necesariamente debe equipararse al dolo consumativo.

b) El comienzo y culminación de la ejecución, -exteriorización de todos los actos ejecutivos que persiguen la consumación objetiva del injusto-; y c) El no perfeccionamiento del tipo de injusto, por razones ajenas a la

30 Bacigalupo, define la tentativa acabada, como aquella en la que el activo, según su plan delictivo, realizó todos los actos necesarios para la consumación, faltando solamente la producción del resultado. BACIGALUPO, Lineamientos de la Teoría del Delito, Buenos Aires, Depalma, 1974, pág. 111.

31 Ver Art. 6, párrafo primero del Código Penal de la República de Nicaragua.

32 MIR PUIG, Derecho Penal Parte General, sexta edición, Barcelona, 2002, pág. 344. 
voluntad del agente-se ejecutan todos los actos necesarios e idóneos para obtener el resultado típico deseado, pero este no se produce por causas externas a la voluntad del sujeto activo-.

Así mismo se aprecia, en la definición brindada por el Pn, que en este supuesto de tentativa acabada, no se hace expresa referencia a la probabilidad de que el sujeto activo, se arrepienta de continuar con la consumación del injusto penal, pero deja abierta la posibilidad de que pueda darse tal supuesto, que en este estadio de la fase ejecutiva, se conoce como arrepentimiento eficaz que impide la consumación del delito, dado que, la norma penal sustantiva plasma que la tentativa acabada, es una forma imperfecta de ejecución del hecho punible, que no logra llegar a la consumación, por causas ajenas a la voluntad del agente, de tal manera que, de forma general podemos deducir y afirmar, que no existirá frustración, cuando el resultado no se produzca por el arrepentimiento del sujeto activo, antes de que se complete la parte objetiva del injusto penal que pretendía consumar, lo cual no implica, que el sujeto activo no deba responder por aquellas actos ejecutados, antes de arrepentirse y que por si solos constituyan delitos independientes, circunstancias que abordaré con posterioridad.

Por su parte, el NCP establece que:

"Hay frustración cuando la persona, con la voluntad de realizar un delito, practica todos los actos de ejecución que objetivamente deberían producir el resultado, y sin embargo este no se produce por causas independientes o ajenas a la voluntad del sujeto ${ }^{33}$ ",

De lo que podemos inferir, que esta definición, así como fue exteriorizado con anterioridad -en lo respectivo a la tentativa inacabada-, mejora la protección al derecho a la presunción de inocencia, que cobija a un sujeto determinado, a quien se le imputa responsabilidad penal, por un hecho punible y a mi criterio, expresamente plantea que la tentativa acabada solo puede presentarse en delitos de resultado, contrario a la tentativa simple que puede apreciarse, incluso en delitos de mera actividad.

Ejemplo de tentativa acabada; A, quien se ha propuesto matar a B, con una escopeta calibre 16, apunta directo a la cabeza del pasivo y presiona el

33 Ver Art. 28 acapite b) del Nuevo Código Penal de la República de Nicaragua. 


\section{Revista de Derecho}

gatillo, momento en que B por un acto reflejo se sube en una escalera, gira y resulta herido en el abdomen, siendo trasladado a un hospital aledaño, en donde le logran salvar la vida.

Considero que para lograr diferenciar una tentativa acabada, de una tentativainacabada, debeatenderseacriteriossubjetivo-objetivo, partiendo del hecho de que en la primera fase ejecutiva se han realizado todos los actos, que son necesarios para consumar un determinado hecho punible, y en la segunda solo se han realizado parte de éstos, no produciéndose en ambas fases, el resultado lesivo al bien jurídico protegido, por razones ajenas a la voluntad del agente, completándose en su totalidad, el tipo subjetivo de la norma penal sustantiva, no así la parte objetiva, pues por su propia naturaleza, siempre ha de quedar imperfecta. ${ }^{34}$

\subsection{Tentativa inidónea y el delito imposible}

En principio debe señalarse, que para un sector de la doctrina, no existe diferenciación entre tentativa inidónea y delito imposible, estudiándoseles como términos iguales, que pueden presentarse en diversos supuestos, por lo que, será criterio del suscrito el mantener que si existe una diferenciación teórica, entre dichos conceptos, por lo que, mi estudio de cada uno de estos actos también imperfectos, será abordado de forma individual.

Así pues, en palabras del maestro Mir Puig, la tentativa inidónea o bien delito imposible, se presenta:

“Cuando por inidoneidad del objeto, de los medios o del sujeto, no podía llegarse a la consumación del delito efectivamente intentado ${ }^{35}$.

De esta definición, se pueden analizar tres aspectos que la componen y que evidentemente resultan independientes entre sí:

El primer elemento es la inidoneidad de los medios, lo que desde mi punto de vista corresponde a la tentativa inidónea, pues comprende el hecho de que un sujeto activo determinado, ejecute una conducta de dar

34 Sobre esta diferenciación teórico práctica, existente entre la tentativa inacabada y la acabada, hay legislaciones contrarias a la nuestra, que han prescindido de realizarla, extendiendo el concepto de tentativa a todo el proceso ejecutivo, desde el comienzo, hasta su terminacion sin consumación; ej; Código Penal Español, que regula en el arto. 16.1 la tentativa, estableciendo "Hay Tentativa, cuando el sujeto da principio a la ejecución del delito directamente por hechos exteriores, practicando todos o parte de los actos que objetivamente deberia producir el resultado, y sin embargo este no se produce por causas independientes a la voluntad del autor. MIR PUIG, Derecho Penal Parte General, sexta edición, Barcelona, 2002, pág. 338.

35 MIR PUIG, Derecho Penal Parte General, sexta edición, Barcelona, 2002, pág. 346. 
principio, o bien ejecutar todos los actos encaminados a la producción de un resultado típico, mismo que no puede producirse, debido a que de acuerdo con sus propiedades objetivas, el medio empleado -arma o herramienta seleccionada para la causación del resultado típico-, para tal efecto, no es adecuado para lograr la consumación material del hecho ${ }^{36}$. De aquí que la no producción del resultado típico, no se presenta por causas fortuitas, que irrumpen el curso causal de una acción exteriorizada por un sujeto activo y que objetivamente pone en peligro el bien jurídico protegido, sino que, dicha acción analizada, no presupone relativamente desde el principio de la ejecución de los actos, un peligro concreto, por imposibilidad del medio.

Ejemplo: A, quien se a propuesto matar a B, compra para tal efecto, una pistola calibre 45, la cual, al momento de ser empleada por el sujeto activo, en el lugar planificado, no logra martillar el proyectil, debido a un desperfecto de fábrica insuperable, no siendo expuesto, desde un punto de vista ex post, el bien jurídico protegido vida.

En lo que respecta al segundo elemento, inidoneidad del sujeto activo o autor de la conducta exteriorizada, esta se da cuando el autor, sin la calificación de autor, realiza la acción típica de un delito que exige una especifica calidad del sujeto activo (Ejemplo: el que en la creencia de ser funcionario, recibe una dadiva) ${ }^{37}$, de lo que se desprende que en este supuesto, ya no puede hablarse de tentativa, por cuanto el actuar del sujeto activo, ha ido mas allá de los actos ejecutivos, pues presupone la consumación de una conducta en la que el sujeto que la ejecuta, por tratarse de un delito especial propio, no tiene las cualidades para ser autor del delito, siendo esto, una forma de delito putativo ${ }^{38}$, en la que quien ejecuta acción, presupone estar cometiendo un delito, en el que ha falta de calidades no puede estar inmerso, lo cual, no implica que no pueda ser responsable de otro delito, en el que su conducta consumada encaje.

36 En este sentido hay quienes afirman que, la acción ejecutiva debe ser mínimamente idónea, pues los actos absolutamente inidóneos no representan un principio de ejecución, porque en modo alguno puede entenderse que con ellos comienza la realización del delito, debiéndose para ello el diferenciar entre idoneidad abstracta, que se identifica con la virtualidad lesiva del hecho del intento, de una concreta, que consiste en su capacidad especifica para alcanzar su consumación. COBO DEL ROSAL / VIVES ANTON, Derecho Penal Parte General, Segunda Edición, Tirant lo Blanch, Valencia, 1987, pág. 501.

37 BACIGALUPO, Lineamientos de la Teoría del Delito, Buenos Aires, Depalma, 1974, pág. 109.

38 El Delito Putativo, puede presentarse cuando el autor cree que se dan en el hecho caracteres típicos que, en realidad, se hallan ausentes del mismo (error inverso acerca del tipo), o bien piensa equivocadamente, que el hecho es delictivo cuando no lo es (error inverso acerca de la significación antijurídica). COBO DEL ROSAL / VIVES ANTON, Derecho Penal Parte General, Segunda Edición, Tirant lo Blanch, Valencia, 1987, pág. 502. 
Ejemplo: A, por un arrebato, devenido de la suposición equivocada de que $\mathrm{B}$, a quien su padre $\mathrm{C}$, le acaba de presentar, es un hermano fuera del matrimonio, le da muerte con un arma de fuego. Esta conducta no será típica del injusto penal de Parricidio, por cuanto, en este el sujeto activo debe estar unido con la víctima por una relación de parentesco -ascendiente, descendiente, hermano, cónyuge o conviviente en unión de hecho estable-, lo cual, no se aprecia en la situación fáctica en cuestión, en la que el activo yerro en su suposición, causando un resultado, que si bien no encaja en el tipo calificado, si es típico del tipo penal base de Homicidio.

En cuanto al tercer y ultimo elemento referido a la inidoneidad del objeto material, es lo que, según mi criterio, configura denominado delito imposible, pues se trata de situaciones fácticas en las que el objeto no permite la consumación, o bien falta en su totalidad ${ }^{39}$, es decir que esta se presenta, cuando en la ejecución de todos los actos que objetivamente son capaces de producir el resultado, este no puede darse, debido a la inexistencia del bien jurídico protegido o por la ausencia del objeto material.

Es importante resaltar que, en cuanto a la inexistencia del bien jurídico protegido en un delito de resultado como el Homicidio, se aprecia una imposibilidad jurídica de la consumación de la conducta punible, por cuanto, el bien jurídico que se tutela, "Vida", no existe al momento en que el sujeto activo exteriorizó su conducta, siendo claro que, quien intenta matar a una persona sin vida, jamás habrá podido encajar en la conducta prohibida de homicidio y mucho menos tentarlo. Sin embargo, en el supuesto de ausencia del objeto material sobre el que recae la acción, el bien jurídico protegido si existe, pero jamás fue concretamente expuesto, pues el sujeto pasivo no se encontraba en el lugar del hecho al momento en que el sujeto activo exteriorizó la conducta prohibida.

Ejemplo-inexistencia de bienjurídico protegido-: A, quien se ha propuesto asesinar a B, penetra en la casa de habitación del segundo, se introduce en su alcoba y aprovechando que esta acostado, le dispara diez veces con un arma de fuego. Sin embargo, B hacia dos horas antes de que A ingresara a la vivienda, había fallecido súbitamente de un derrame cerebral.

39 BACIGALUPO, Lineamientos de la Teoría del Delito, Buenos Aires, Depalma, 1974, pág. 109. 
Ejemplo -ausencia del objeto material sobre el que recae la acción-: $\mathrm{A}$, quien se ha propuesto asesinar a $\mathrm{B}$, penetra en la casa de habitación del segundo, se introduce en su alcoba y creyendo que esta acostado, le dispara dos veces con un arma de fuego. Sin embargo, B no se encontraba en la alcoba, siendo las almohadas de este, las víctimas de A.

El Pn regula la tentativa inidónea, no con este nombre, como una forma en que el Juez de la causa puede atenuar la responsabilidad penal, en aquellos casos en que los actos encaminados a la ejecución de un delito, sean inadecuados para su efectiva consumación ${ }^{40}$, lo cual denota que, nuestra legislación penal vigente, deja a criterio del judicial, el apreciar si una conducta exteriorizada a través de medios inadecuados, es relativa o absolutamente inidónea, y que en base a ese criterio personal imponga una medida de seguridad al sujeto activo de la misma - enfermos mentales o intoxicados-, pues en ambos casos tiene facultad para hacerlo.

$\mathrm{Al}$ respecto, el NCP se inclina por no realizar diferenciaciones entre tentativa inidónea y delito imposible, eximiendo de responsabilidad en ambos casos, cuando fuere absolutamente imposible la consumación del delito ${ }^{41}$, lo cual, no deja claro que pasa en aquellas situaciones fácticas, en la que la imposibilidad de consumar la conducta prohibida sea relativa, siendo el criterio adoptado por el NCP evidentemente objetivo, pues presupone que la conducta ejecutada por el activo y analizada ex ante, no era capaz, desde el principio, de exponer al bien jurídico protegido, por lo que, no puede sancionarse. ${ }^{42}$

En este sentido considero, que tanto en la tentativa inidónea, como en el delito imposible hay una manifestación de la voluntad delictiva, en la que si bien, puede que de manera absoluta, nunca se haya puesto en peligro al bien jurídico protegido, en ciertos casos concretos la puesta en peligro puede presentarse relativamente, lo cual, trae consigo un sentimiento de inseguridad ciudadana merecedora de una intervención de parte del ius puniendi del Estado, por lo que, respecto de la tentativa inidónea y el delito imposible por ausencia del objeto sobre el que recae la acción, me inclino

$40 \quad$ Ver Art. 12 del Código Penal de la República de Nicaragua.

41 Art. 30 NCP." Delito imposible. No será sancionada la tentativa o la frustración cuando fuere absolutamente imposible la consumación del delito ".

42 En cuanto al criterio objetivo, Mir Puig señala que este es el mas adecuado, por cuanto el derecho penal debe penar comportamientos que ex ante, al realizarse, aparezcan como peligrosos para bienes jurídicos, siendo la tentativa inidónea ex ante peligrosa, en la medida, en que para el espectador objetivo, situado en el, lugar del autor, hubiera podido no concurrir en ella la inidoneidad y producirse por su virtud el delito. MIR PUIG, Derecho Penal Parte General, sexta edición, Barcelona, 2002, pág. 347. 
por un criterio subjetivo-objetivo, en el que se valore, no solo ex antes, si objetivamente el bien jurídico fue o no expuesto, sino que subjetivamente se tome en cuenta que el sujeto activo desconocía durante la ejecución, acerca de la imposibilidad de realización de la conducta prohibida -por inidoneidad del medio o ausencia del objeto-, y que ex post, creó con su actuar, un sentimiento de inseguridad perceptible por quien pudo ser el sujeto pasivo, e incluso por la sociedad en su conjunto, lo que en mayor o menor medida, perturba al bien jurídico protegido.

Además debe tomarse en cuenta, que puede darse el caso en que el sujeto activo pueda concebir la realización del injusto penal de Homicidio, mediante la implementación de un medio relativamente inidóneo, pues en personas fácilmente impresionables, que tengan problemas cardiacos, o en el caso de los diabéticos, los medios aparentemente inadecuados para obtener el resultado, pueden tornarse los mas idóneos para la consumación de una determinada conducta prohibida, por lo que, debe analizarse cada caso concreto, con apego al criterio valorativo más adecuado y no encasillar la resolución de todas las situaciones fácticas, a una sola corriente. Por ello, en cuanto al delito imposible, por inexistencia del bien jurídico protegido, considero que el criterio a seguir debe ser el objetivo, pues en este supuesto no puede hablarse siquiera de puesta en peligro abstracto, debido a que ex ante del inicio de los actos ejecutivos, por parte del sujeto activo, el bien jurídico protegido ya había desaparecido, razón por la cual no pudo ser expuesto, y consecuentemente, al no existir ex post al delito tampoco pudo ser perturbado, de tal manera, que la conducta no es siquiera típica, siendo esta el principal fundamento de su impunidad.

También podría presentarse el caso en que la inidoneidad de la tentativa sea evidentemente notoria, al punto de que para cualquier espectador objetivo, colocado en la situación de autor, sea imposible suponer la posibilidad de puesta en peligro del bien jurídico protegido, lo cual, se conoce con el nombre de Tentativa Irreal ${ }^{43}$, misma que no se encuentra regulada en el Pn y que puede ser subsumida en lo establecido en el NCP, respecto del delito imposible, por ser absolutamente impune.

Ejemplo: A, quien se ha propuesto matar a B, fabrica un muñeco de algodón de este, y le clava, cincuenta alfileres.

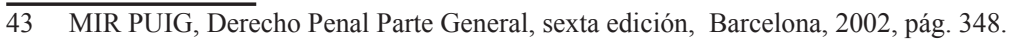




\section{Iter criminis en la omisión}

En primer lugar, haremos referencia a la omisión pura o simple omisión, que se presenta cuando el sujeto activo omite una determinada acción, pese a que podía haberla ejecutado ${ }^{44}$, lo cual denota que, en primer lugar el derecho penal no exige actos heroicos, de tal manera que, el sujeto activo debe dejar dolosamente de hacer algo, que en principio la ley le obliga a realizar y que en una determinada situación fáctica, no suponga un riesgo para su persona, siendo claro que en este tipo de omisiones, el acto exigido por la norma penal sustantiva se consuma con un hecho instantáneo, razón por la cual, no es posible el dividir la conducta exteriorizada por el sujeto activo, en iter fases, de tal manera que en estos supuestos no puede hablarse de actos preparatorios o ejecutivos.

Ejemplo: A, observa que B golpea brutalmente a la menor C, y sin embargo no le presta auxilio. El delito de omisión se consumo instantáneamente, al momento en que el sujeto activo, omitió el deber de socorro, respecto de la víctima, no siendo importante, a efectos de la configuración del tipo omisivo, el resultado que se produce por el actuar activo del agresor sobre el sujeto pasivo.

En lo que respecta al delito en comisión por omisión, es preciso hacer notar que estos pueden o no estar expresamente tipificados por la norma penal sustantiva, pero sin duda, han sido reconocidos por la doctrina y la jurisprudencia, en atención al hecho de que la omisión realizada por el agente, quien tiene un especial deber de garante, respecto del bien jurídico protegido, equivale a la causación activa del resultado típico, de lo que se desprende que, posee similitudes estructurales, respecto del tipo de omisión pura como lo son la ausencia de una acción determinada o esperada y la capacidad de realizarla sin riesgo para su persona, presentando las siguientes diferencias; a) Puede o no estar tipificado por la ley penal. b) La exigencia de parte del omitente de una posición de garante, -estrecha relación que existe entre el omitente y el bien jurídico protegido-, que convierte al tipo impropio de omisión, en un tipo especial, por cuanto, solo pueden ejecutarlos un determinado numero de autores ${ }^{45}$.

44 La estructura del tipo de omisión consta de tres elementos: a) La situacion tipica, entendida como la conducta delictiva descrita por la Ley, b) La ausencia de una acción determinada, y c) La capacidad de realización de la conducta, mediante la cual se condiciona, el deber de socorro del autor, a que el pudiera hacerlo. MIR PUIG, Derecho Penal Parte General, sexta edición, Barcelona, 2002, pág. 309 y 310.

45 En cuanto a la posición de garante, y la estrecha relación que presupone existe entre el autor de la omisión y el bien jurídico protegido, se toman elementos como el cuidado de una fuente de peligro 


\section{Revista de Derecho}

c) La producción, a consecuencia directa de la omisión del agente, de de un resultado típico. d) Posibilidad de evitar el resultado típico, a través de la ejecución de la acción esperada ${ }^{46}$.

Al caracterizarse estos delitos impropios de omisión, por la causación activa de un resultado lesivo a un bien jurídico protegido, puede hablarse de fragmentación de etapas de preparación y ejecución de un injusto penal especifico, de tal manera, que el problema radica en determinar el comienzo de los actos omisivos, que permiten dar principio a la ejecución de la conducta prohibida.

En este sentido, hay quienes afirman que la omisión comienza cuando de manera actual, el ordenamiento jurídico penal, le exige al agente garante del bien jurídico protegido- que actué y evite con su acción la lesión efectiva de su deber, lo cual no realiza, causando el resultado lesivo, criterio que nos hace pensar en cuando se da esa actual exigencia obrar, de parte del ordenamiento jurídico penal, si en el primer momento en el que el omitente dejo de hacer lo que por su posición de garante debía hacer, o bien, en el último momento en que aún su intervención es posible y eficaz para lograr evitar el resultado ${ }^{47}$. En este sentido, considero acertado el criterio que plantea que el comienzo de la tentativa, esta dado desde el momento en que la inactividad del omitente, presupone un peligro concreto al bien jurídico protegido del que él es garante, siendo capaz de producir una lesión al mismo, o bien, cuando por una acción anterior a su omisión, ha puesto en peligro al bien jurídico protegido.

ElPn, estableceexpresamentela punibilidad dela omisión en todos aquellos supuestos establecidos por la norma penal sustantiva ${ }^{48}$, brindándonos una definición que solo abarca a la omisión pura ${ }^{49}$, consistente en dejar de hacer lo que manda la ley. Al respecto, es claro que en nuestra legislación penal

frente a la generalidad de bienes jurídicos, referido a la persona que está encargada de cuidar una determinada fuente de peligros frente a la generalidad de los bienes jurídicos, para los cuales de esa fuente de peligro puede derivarse un daño. Cuidado de un bien jurídico, frente a los peligros que puedan amenazarlos, dentro de la que se incluyen los deberes de cuidado y protección de bienes juridicos que corresponden a los funcionarios y aquellos deberes que tienen por objeto el cuidado de personas nesecitadas. BACIGALUPO, Lineamientos de la Teoría del Delito, Buenos Aires, Depalma, 1974, pág. 159, 162 y 163.

46 MIR PUIG, Derecho Penal Parte General, sexta edición, Barcelona, 2002, pág. 311.

47 CASTILlo GONZÁLEZ, Tentativa y Desistimiento Voluntario, San José Costa Rica, Editorial Jurídica Continental, 2003, pág. 68.

48 Art. 1 Pn: "Toda acción u omisión calificada y penada por la ley constituye delito o falta, según su gravedad".

49 Art. 25 Pn: " En los delitos de omisión se consideran responsables las personas que dejan de hacer lo que manda la Ley. 
vigente, la comisión por omisión, no esta determinada por la norma penal sustantiva, pero en la dogmática y la jurisprudencia, esta es totalmente aceptada, como una de las formas de consumación de injustos penales, en las que la pena, es equiparada a la causación activa del resultado lesivo al bien jurídico.

El NCP, regula expresamente el delito omisivo y el de comisión por omisión, plasmando en su párrafo primero:

' 'Los delitos ofaltas pueden ser realizados por acción u omisión. Aquellos que consistan en la producción de un resultado, podrán entenderse realizados por omisión sólo cuando el no evitarlo infrinja un especial deber jurídico del autor y equivalga, según el sentido estricto de la ley, a causar el resultado.' 50

Respecto de este primer párrafo, considero que la norma penal sustantiva, únicamente se esta refiriendo a la punibilidad de los injustos penales que sean cometidos en comisión por omisión, por cuanto, expresamente plantea el especial deber jurídico -garante- que debe tener el omitente, en relación con el bien jurídico protegido, al momento en que no realice la acción esperada, de tal manera, que no todos los sujetos, pueden estar inmersos en esta prohibición, sino solo aquellos que sean garantes, lo cual no implica, que no será punible en delitos de resultado, la omisión pura o simple, dado que si bien este articulo no define en que consiste la omisión pura, esta si se encuentra regulada en diversos artículos del NCP, en los que claramente se expresa lo que el omitente, que no es garante, debe dejar de hacer -omitir el deber de auxilio, cuando no exista riesgo para su persona, a un pasivo que lo necesite o a un menor perdido o abandonado, cuya vida este en peligro-, para configurar el tipo omisivo ${ }^{51}$. En este sentido debe resaltarse que el NCP, incluye delitos de omisión que están dirigidos a aquellos sujetos que pudiendo hacerlo, no impidan o no promuevan la persecución de injustos penales, lo que demuestra una mayor regulación del tipo omisivo, en relación al Código Penal vigente.

El segundo párrafo del precitado artículo reza:

En aquellas omisiones que, pese a infringir su autor un deber jurídico especial, no lleguen a equivaler a la causación activa del resultado, se impondrá la pena agravada hasta el doble del límite máximo de la del

50 Ver Art. 23 párrafo primero del Nuevo Código Penal de la República de Nicaragua.

51 Ver Art. 160 del Nuevo Código Penal de la República de Nicaragua. 
delito omisivo. No obstante, dicha pena no podrá superar en ningún caso el límite mínimo de la pena asignada al delito de resultado que correspondería aplicar si hubiera comisión por omisión' "52

Aquí la norma penal sustantiva, sigue refiriéndose a delitos en comisión por omisión, pues el autor debe tener un deber jurídico especial, respecto del bien jurídico protegido -ser garante-, pero, plantea un supuesto en que la inactividad del omitente no puede equivaler a la causación activa del resultado, lo cual a efectos de pena, tiene gran relevancia, pues en el primer supuesto de comisión por omisión, la pena es la misma que equivale al delito de resultado ejecutado de forma activa, siendo la pena a aplicar en esta situación fáctica, en apego estricto a la norma penal sustantiva, agravada hasta el doble del limite máximo de la del delito omisivo -entiéndase omisión pura, misma que fue definida con posterioridad, siendo la consecuencia jurídica aplicable a cada caso concreto, la base de la punibilidad de este supuesto-, pena que lógicamente, no podrá ser mayor a la pena mínima establecida al delito de resultado, causado en el primer supuesto de comisión por omisión.

Considero que este articulo, si bien no define en que consiste la omisión pura -realizando la tipificación de la conducta omisiva de la ley, en posteriores artículos-, y resulta complejo al momento de analizar la posible pena a imponer en los dos supuestos de comisión por omisión que plantea, hace una expresa regulación del mismo, lo cual, es notoriamente novedoso en relación al Pn que no hacia mención del delito en comisión por omisión -únicamente de la omisión pura-, por lo que, puedo afirmar que efectivamente el NCP, supera los vacíos que posee el Pn en lo que hace al delito omisivo $\mathrm{y}$ a las formas en que este puede presentarse, pero a su vez falla en la redacción técnica del mismo, al momento en que no establece con claridad la sanción penal a imponer en los supuestos fácticos de impropia omisión analizados con anterioridad.

Ejemplo de comisión por omisión: A, quien es padre adoptivo del menor $\mathrm{B}$, aprovechando que este no sabe nadar, lo invita a una piscina, retándolo para que se lance al agua, lo cual el sujeto pasivo realiza, y al observar A, que el sujeto pasivo se ahoga, omite la acción de salvamento y se retira del lugar.

52 Ver Art. 23 párrafo segundo del Nuevo Código Penal de la República de Nicaragua. 
Revista de Derecho

\section{Desistimiento voluntario $y$ arrepentimiento eficaz que impide la consumación del delito.}

En principio el desistimiento voluntario de la consumación del injusto penal, consiste en la no continuación libre y espontánea, de parte del sujeto activo, de los actos exteriorizados por este, y que están encaminados a la producción del resultado lesivo al bien jurídico protegido, por lo que, en principio este únicamente puede presentarse en una tentativa inacabada.

De aquí se desprende que se requieren tres requisitos para que pueda presentarse el desistimiento: a) Omisión de continuar con la realización del hecho tendiente a la consumación, b) Voluntariedad del desistimiento, en condiciones que posibiliten la consumación del injusto penal, y c) $E l$ desistimiento debe ser definitivo, en el sentido que el sujeto activo no debe pensar en la posibilidad de continuar la ejecución de los actos, en mejores condiciones ${ }^{53}$. Respecto del primer requisito del desistimiento, este se basa en la posibilidad que tiene el agente de desistir voluntariamente, de la ejecución de los actos encaminados a la producción del resultado típico, imposibilitando con su omisión, la consumación dela conducta prohibida ${ }^{54}$, siendo fundamental que el sujeto activo, al momento de desistir, solo haya ejecutado parte de los actos que objetivamente permitirían obtener el resultado.

En cuanto a la voluntariedad del agente al momento del desistimiento, existen dos teorías que tratan de explicarlo: teoría psicológica-parte de la formula de Frank, en la que el desistimiento es voluntario siel sujeto activo no quiere alcanzar la consumación aunque pueda, siendo involuntario, sino quiere porque no puede- y la teoría valorativa - la voluntariedad del desistimiento, solo es admisible si obedece a un motivo susceptible de una valoración positiva. Esta se apoya en criterios cuantitativos, (toma en cuenta el plan delictivo del sujeto activo y lo relaciona con lo objetivamente acaecido); éticos, ( el desistimiento voluntario implica la renuncia total a continuar ejecutando el injusto penal, misma que debe producirse a consecuencia de la voluntad libre, no coartada o impuesta por las circunstancias del hecho, y que este fundada en motivos éticos

53 MUÑOZ CONDE,/ GARCÍA ARÁN, Derecho Penal Parte General, 3ra. ed. Valencia, España, Tirant lo Blanch, 1998, pág. 473.

54 QUIROS PIRÉZ, Manual de Derecho Penal, Editorial Félix Varela, San Miguel, El Mazón y Basarrate, El Vedado, Ciudad de la Habana, pág. 111, 112 y 113. 
positivos valiosos); jurídicos, (se fundamenta en la posibilidad otorgada al sujeto activo, que ha reconocido en la ejecución de sus conductas, el valor e importancia del ordenamiento jurídico)- .55

$\mathrm{Al}$ respecto, considero que el criterio más acertado debe ser el ético, por cuanto es el que deja entrever con más claridad, la voluntad del sujeto activo de no continuar con la ejecución de los actos típicos, debido al reconocimiento de sus valores, y no por temor de la posible represalia que pueda recibir de parte del ordenamiento jurídico penal, o bien por la imposibilidad de continuar con la consumación del hecho en ese momento determinado, o por los peligros que conlleva, el continuar con la ejecución de la conducta, supuestos en los que el desistimiento no puede ser impune.

En lo que tocante al tercer requisito referido a la definitividad del desistimiento, el criterio planteado por el maestro Bacigalupo, obedece a una consideración abstracta, que dicho sea de paso considero la más acertada, por cuanto el autor debe abandonar, no solo en concreto el hecho típico que se proponía consumar, sino la posibilidad de continuar la ejecución con posterioridad, cuando varíen las circunstancias que en un primer momento, le han hecho desistir de la consumación, pues en caso contrario, se dejaría impune una conducta que presupone un peligro concreto y subsistente, para el bien jurídico protegido y en la que el sujeto activo claramente no ha tomado consciencia de la ilicitud de la conducta por él exteriorizada.

En cuanto, a la consecuencia jurídica que trae consigo el desistimiento voluntario, esta radica en la impunidad de la tentativa inacabada del delito que se proponía consumar, esto debido a que si bien, ex ante al delito, existe peligrosidad en la conducta prohibida iniciada por el agente, ex post, el resultado manifiesto no hace necesaria la imposición de la pena ${ }^{56}$, es decir, que debe valorarse el hecho que el autor, durante la ejecución de la conducta, haya recapacitado y se muestra obediente de lo establecido por el ordenamiento jurídico penal, pues con ello se logra el fin preventivo que persigue un derecho penal de acto, en el que su intervención será la ultima ratio y con fines no sancionadores, sino, de prevención en general o especifico, siendo la pena un instrumento de resocialización del agente, y que a posteriori permitirá su reinserción en la sociedad, al hacerlo comprender la antijurícidad de su conducta, lo cual, no seria lógico aplicar,

56 MIR PUIG, Derecho Penal Parte General, sexta edición, Barcelona, 2002, pág. 350.

55 MIR PUIG, Derecho Penal Parte General, sexta edición, Barcelona, 2002, pág. 350. 
a un sujeto que voluntariamente a comprendido la ilicitud de su actuar y que por ende no la continua. Sin embargo, es preciso hacer notar que la impunidad devenida del desistimiento del delito intentado, no excluye de ninguna manera la punibilidad de la conducta anterior al desistimiento y que por si sola configure un delito consumado, misma que recibe el nombre de tentativa cualificada ${ }^{57}$

Ejemplo de desistimiento voluntario: A, quien se ha propuesto asesinar a $\mathrm{B}$, se persona en el lugar planificado para consumar la conducta prohibida, saca el arma destinada para obtener el resultado, apunta al sujeto pasivo, pero voluntaria y espontáneamente, decide no continuar con la ejecución, retirándose del lugar.

Ejemplo de tentativa cualificada: A, quien se ha propuesto asesinar a B, disparándole desde la azotea de un edificio cercano al trabajo del sujeto pasivo, ingresa a dicho local, forzando las cerraduras de las puertas de acceso que le impiden llegar a la azotea. Una vez estando en el lugar planificado, desiste libre y espontáneamente de continuar los actos que objetivamente permitirían obtener el resultado lesivo al bien jurídico protegido. De esto se infiere, que si bien el sujeto activo no responderá de la tentativa inacabada de asesinato, será responsable del delito instantáneo de daños a la propiedad, ocasionado a las cerraduras de las puertas del local por el elegido.

\section{En cuanto al arrepentimiento eficaz que impide la consumación}

del delito, se considera que este se produce, una vez que el sujeto activo ha exteriorizado todos los actos objetivamente capaces de producir el resultado lesivo al bien jurídico protegido y de forma activa, espontánea y voluntaria, decide evitar el resultado típico.

De aquí pueden desprenderse tres requisitos: a) La realización activa, de actos tendientes a evitar el resultado lesivo al bien jurídico protegido; b) La voluntariedad y espontaneidad de impedir activamente, y por los medios a su alcance el resultado, pues en este supuesto, el sujeto activo no puede pensar en la posibilidad de continuar la ejecución del delito con posterioridad, debido a que ya ha ejecutado todos los actos tendientes a consumar la conducta prohibida, por lo que, su decisión esta indicada a evitar el resultado o no; c) El arrepentimiento activo debe presentarse antes de haberse consumado el delito.

57 COBO DEL ROSAL / VIVES ANTON, Derecho Penal Parte General, Segunda Edición, Tirant lo Blanch, Valencia, 1987, pág. 503. 
Sin embargo, puede suceder durante el arrepentimiento eficaz, únicamente en tentativa acabada, que exista lo que se conoce error en el arrepentimiento, en los que el resultado se produce aún y cuando, el sujeto activo realizó una serie de actos tendientes a evitar la consumación del injusto penal. En principio deben tomarse en cuenta, al momento de valorar las circunstancias de cada situación fáctica en concreto, si los actos exteriorizados por el agente, para evitar el resultado, fueron inútiles debido a una imprudencia, debiéndose en tal caso imponer responsabilidad penal con base a esa forma de imputación, o bien si la consumación de la conducta obedece a causas fortuitas, en las que deberá plantearse la atenuante o eximente de responsabilidad penal que corresponda ${ }^{58}$.

Al igual que en el desistimiento voluntario, la principal consecuencia que trae consigo el arrepentimiento eficaz de consumar la conducta típica, radica en la no imposición de la sanción penal, respecto del delito que mediante la ejecución de todos los actos objetivamente adecuados, pretendía consumar, y antes de lograrlo se arrepintió y evitó directamente o a través de terceros, la producción del resultado típico. De tal manera que en este supuesto, también son punibles aquellos actos anteriores al arrepentimiento eficaz del agente, que por si solos constituyan injustos penales independientes - tentativa cualificada-, mismos que desde mi punto de vista se presentan con mayor anuencia en el arrepentimiento, por tratarse de una tentativa acabada.

Ejemplo de arrepentimiento eficaz: A, quien se ha propuesto asesinar a B, se persona en el lugar planificado para consumar la conducta prohibida, saca el arma destinada para obtener el resultado, apunta y con animus necandi le dispara al sujeto pasivo, lesionándole el hombro, momento en que A, voluntaria y espontáneamente, decide no consumar -pudiendo hacerlo- la parte objetiva del tipo, retirándose del lugar.

Ejemplo de tentativa cualificada: A, quien se ha propuesto asesinar a B, se persona el lugar planificado para consumar la conducta prohibida, saca el arma destinada para obtener el resultado lesivo al bien jurídico protegido, apunta y con animus necandi le dispara al sujeto pasivo, lesionándole el hombro, momento en que A, voluntaria y espontáneamente, decide no consumar - pudiendo hacerlo- la parte objetiva del tipo, retirándose del lugar. De esto se infiere, que si bien el sujeto activo no responderá de la

58 MUÑOZ CONDE,/ GARCÍA ARÁN, Derecho Penal Parte General, 3ra. ed. Valencia, España, Tirant lo Blanch, 1998, pág.473. 
tentativa acabada de asesinato, será responsable del delito de resultado de lesiones, ocasionado al pasivo de la acción.

Ejemplo de fracaso en el arrepentimiento: A, quien se ha propuesto asesinar a B, se persona el lugar planificado, saca el arma, apunta y con animus necandi le dispara al sujeto pasivo, lesionándole en el abdomen, momento en que A, voluntaria y espontáneamente, decide no consumar - pudiendo hacerlo- la parte objetiva del tipo, y traslada a B al hospital más cercano, mismo que al ingresar al hospital fallece, debido a la perdida masiva de sangre.

Respecto de estas formas de evitación voluntaria de la consumación del injusto penal, el Pn, no define cuando puede darse el desistimiento voluntario de la consumación del injusto penal, pero prevé la posibilidad de que este pueda presentarse durante la ejecución de algunos actos ejecutivos, al plasmar el desistimiento voluntario, dentro de la definición de tentativa inacabada, planteando que la punibilidad de los actos que no logran obtener el resultado, esta en dependencia de si este, no acaeció por causas independientes al propio y voluntario desistimiento del agente ${ }^{59}$. Del arrepentimiento eficaz, que únicamente puede producirse en tentativa acabada, el Pn no hace expresa regulación, pero si deja abierta en pro reo, la posibilidad de que este, pueda ser apreciado en la definición legal de frustración, al plantear que en caso de que el agente realice todos los actos objetivamente necesarios para obtener el resultado típico y este no se produce, la punibilidad de la forma imperfecta también esta en dependencia de si el resultado no se produjo por causas independientes a la voluntad del agente ${ }^{60}$.

Por su parte el NCP, establece expresamente, como eximente de responsabilidad penal, el desistimiento voluntario de la consumación del delito, así como el arrepentimiento eficaz que impide la consumación, al plantear que:

'Quedará exento de responsabilidad penal por la tentativa o la frustración, la persona que desista eficazmente de la ejecución o consumación del delito por su propia voluntad ${ }^{61^{\prime \prime}}$.

59 Ver art. 6 párrafo segundo del Código Penal de la República de Nicaragua.

60 Ver art. 6 párrafo primero del Código Penal de la República de Nicaragua.

61 Ver art. 29 párrafo primero del Nuevo Código Penal de la República de Nicaragua. 
De tal manera, que la norma penal, exige para la impunidad de las formas imperfectas de la consumación del delito -tentativa acabada e inacabada-, los siguientes requisitos; a) Que el sujeto activo no continué con la ejecución de los actos objetivamente necesarios para la producción del resultado -desistimiento voluntario en tentativa inacabada; b) Que el agente una vez que ha ejecutado todos los actos objetivamente adecuados para la producción del resultado, pudiendo hacerlo, evite activamente la consumación -arrepentimiento eficaz en tentativa acabada-; c) Que tanto el desistimiento como el arrepentimiento eficaz, deben presentarse por la propia voluntad del agente y antes de la consumación del injusto penal.

En lo que hace a la segunda parte de esta regulación, que establece:

“...Sin embargo, responderá penalmente por los actos de ejecución que por sí mismos ya sean configurativos de delito"“2.

La ley, plasma expresamente la punibilidad de la tentativa cualificada que ya fue explicada con anterioridad, y que sin duda representa un gran avance, en cuanto a regulación de las conductas punibles, respecto del código penal vigente.

Así mismo, el $N C P$, establecela posibilidad de exclusión de responsabilidad penal, cuando se presente un desistimiento voluntario o bien un arrepentimiento eficaz, encaminados respectivamente, ala no continuación o evitación de la producción del resultado típico, en una situación fáctica en la que existan diversos autores, regulándose que:

"Si en el hecho intervienen varios sujetos, quedarán exentos de responsabilidad penal sólo aquel o aquellos que voluntariamente desistan de la ejecución e impidan o intenten seriamente impedir la consumación ".63

De lo que se desprende que la eficacia excluyente de estas formas de evitación voluntaria de la consumación del delito, únicamente alcanzan al o los que voluntariamente desisten o se arrepienten de consumar la conducta prohibida. Respecto de esta regulación, la norma penal plantea que;

62 Ver art. 29 párrafo primero del Nuevo Código Penal de la República de Nicaragua.

63 Ver art. 29 párrafo segundo del Nuevo Código Penal de la República de Nicaragua. 
Revista de Derecho

“La exención prevista en los apartados anteriores no alcanzará a la responsabilidad que pudiera existir si los actos ya ejecutados fueran por sí mismos constitutivos de otro delito o falta. "64

Lo que a criterio del suscrito, se refiere nuevamente al hecho de que la eximente solo excluye responsabilidad por el delito tentado y respecto del que se desistió o se arrepintió, no así de la tentativa cualificada.

\section{Consumación.}

La consumación, es aquella que acaece una vez que se ha realizado la totalidad de los elementos del tipo de injusto de que se trate, incluyendo las actividades descritas por el y al resultado típico ${ }^{65}$, es decir que, para que un delito se entienda consumado en delitos de resultado, como es el caso que nos ocupa -homicidio y asesinato-, se requiere que el sujeto activo realice todos los actos objetivos y subjetivos, descritos por el tipo de injusto determinado, y que como consecuencia de ello, se produzca el resultado lesivo, al bien jurídico protegido.

La anterior definición de consumación, es la que se conoce como formal, pues plantea directamente que el injusto penal se entiende consumado, con la lesión efectiva del bien jurídico protegido, es decir con la culminación del supuesto de hecho descrito por la norma penal sustantiva. Sin embargo, existe otro tipo de consumación conocida como material, agotamiento o terminación del delito, en la que el sujeto activo, no solo realiza todos los elementos típicos, sino que consigue satisfacer la intención que perseguía ${ }^{66}$, de tal manera, que el agotamiento presupone que el autor que ha exteriorizado la conducta punible, ha logrado consumarla y mas aún, ha conseguido satisfacer plenamente su finalidad delictiva.

En cuanto al agotamiento, se plantea que generalmente solo puede darse en delitos que tiendan a perseguir una finalidad posterior a la consumación formal del hecho,-delitos de apoderamiento, que persiguen una vez que se presenta la consumación formal de la conducta típica, el poder lucrarse de la cosa ilícitamente en su poder-, sin embargo, es mi criterio que, si bien no puede apreciarse el agotamiento en el tipo de resultado base de

64 Ver Art. 29 párrafo tercero del Nuevo Código Penal de la República de Nicaragua.

65 COBO DEL ROSAL / VIVES ANTON, Derecho Penal Parte General, Segunda Edición, Tirant lo Blanch, Valencia, 1987, pág. 503.

66 MUÑOZ CONDE,/ GARCÍA ARÁN, Derecho Penal Parte General, 3ra. ed. Valencia, España, Tirant lo Blanch, 1998, pág. 459. 
Homicidio, si puede apreciarse consumación material en el calificado de Asesinato, por cuanto, el Pn plasma como una de las características propias de este injusto penal, la posibilidad de que el sujeto activo, lo haya ejecutado, por un interés distinto al de causar simplemente la muerte del sujeto pasivo - por precio o recompensa remuneratoria ${ }^{67}$, de tal manera, que el tipo de asesinato con base a esta causal, estará formalmente consumado con la muerte del sujeto pasivo y se agotara cuando el sujeto activo reciba el precio o recompensa remuneratoria.

El Pn establece expresamente la punibilidad del delito consumado y de las formas imperfectas de la consumación del injusto penal ${ }^{68}$, pero no define en que consiste la consumación, lo cual obedece al hecho, de que cada tipo penal plantea con claridad, la consumación de la conducta típica. Así mismo, nuestra legislación penal vigente, no considera necesario, que se de el agotamiento del delito, para que la acción exteriorizada por el agente, que objetiva y subjetivamente ha configurado el tipo, se entienda consumada y merecedora de sanción penal por la comisión completa del tipo.

Por su parte el $N C P$, también establece la punibilidad del delito consumado y de las formas imperfectas de la consumación del injusto penal ${ }^{69}$, pero a diferencia del Pn, plantea expresamente una definición legal de lo que se entiende por consumación, estableciendo que:

"Un delito se considera consumado cuando el autor realiza todos los elementos del delito ". ${ }^{70}$

Definición de la que se infiere que, el sujeto activo debe ejecutar una conducta que cumpla con la parte objetiva y subjetiva del injusto penal ad hoc, y luego de esto es que se podrá entender como consumado el delito, no tomándose en cuenta si este logró o no la satisfacción plena de su finalidad delictiva -consumación material-.

A, quien se ha propuesto matar a B, le dispara en la cabeza, obteniendo instantáneamente el resultado muerte.

67 Art. 134 Pn: 'Es reo de asesinato el que matare a alguna persona concurriendo cualquiera de las circunstancias siguientes: 2) Por precio o promesa remuneratoria'"

68 Ver arto. 6 del Código Penal de la República de Nicaragua.

69 Art. 27 del NCP que cita: 'Son punibles: el delito consumado, el delito frustrado y la tentativa de delito. Las faltas, excepto aquellas contra las personas y el patrimonio, se castigarán solamente cuando hayan sido consumadas'.

70 Ver Art. 28 acapite a) del Nuevo Código Penal de la República de Nicaragua. 
Ejemplo de delito consumado material: A, quien es sicario de profesión, acepta la tarea de asesinar a B, por la suma de cien dólares netos, de los cuales, recibirá el $50 \%$ al inicio del trabajo y el otro $50 \%$ luego de que se produzca el resultado muerte. De tal manera, que el sujeto activo consumara formalmente el asesinato con la muerte del sujeto pasivo y lo agotara, cuando reciba el dinero restante, por la culminación de su trabajo.

\section{Conclusiones.}

- El conocimiento del iter criminis, representa sin duda una de las principales herramientas que debe manejarse al momento de tratar de determinar el grado de responsabilidad penal que tiene el agente, en determinadas situaciones fácticas, en las que el resultado se produjo por distintas causas subjetivas y objetivas, o bien cuando este no se consumo por causas ajenas a la voluntad del agente y en las que la parte subjetiva se consuma, quedando inconclusa la parte objetiva del tipo, o en situaciones de mayor complejidad, que exigen de parte del litigante, Juez, Fiscal o estudioso del derecho, un nivel de mayor conocimiento al momento de solicitar, así como resolver, con bases jurídicas, lo que en derecho a cada quien corresponde.

- El camino del delito, consiste en la punibilidad de una serie de conductas activas u omisivas, que han sido exteriorizadas por un sujeto activo y que ofenden bienes jurídicos tutelados por la norma penal sustantiva, a fin de que estas puedan prevenirse, y con ello aminorarse en cierta medida, el índice delictivo que existe en cada sociedad organizada, y que define estadísticamente la seguridad jurídica de sus ciudadanos.

Sin embargo, las iter fases no pueden presentarse en todos los delitos de la parte especial de la ley penal, razón por la cual, la casuística giró en torno a los delitos de resultado de homicidio y asesinato, en los que claramente se demostró, la practicidad social que tiene lo jurídico, desde el primer momento en que los sujetos activos, deciden exteriorizar conductas punibles, sin medir las consecuencias jurídicas de sus actos externos, dejándose entrever, en los casos que la ley lo permite, la relevancia que tiene que el sujeto activo tome conciencia de los actos que ejecuta y por ello decida no continuarlos, aún cuando se encuentre inmerso en el inicio de una conducta punible, pues esa toma de conciencia de lo éticamente correcto, antes de la consumación formal del injusto penal, trae consigo un reconocimiento jurídico de parte de la ley penal, que en determinados casos aminora e incluso excluye la responsabilidad penal. 


\section{Revisla de Perecho}

\section{Recomendaciones.}

- A las partes procesales, en materia penal, que diario tienen como trabajo la aplicación de la norma penal sustantiva, a casos concretos, estudien a fondo el iter del delito, pues si bien la experiencia adquirida con la práctica diaria, es de vital importancia, esta es totalmente equivoca y desenfocada, sin la dirección que nos brinda el conocimiento dogmático, no solo de conceptualizaciones otorgadas por la doctrina -mayoritaria-, respecto de las fases que debe seguir el sujeto activo durante la ejecución del injusto penal, sino, de las problemáticas que se suscitan al momento de valorar los aspectos subjetivos y objetivos, de la conducta exteriorizada por el activo y que puede o no llegar a la consumación. Además, dicho estudio les será de suma ayuda al momento en que entre en vigencia el Nuevo Código Penal, pues este exige un nivel de conocimiento dogmático mayor al del Código Penal vigente, al plantear nuevos delitos, nuevas formas de llevarlos a cabo, así como nuevas y complejas circunstancias que pueden excluir o aminorar la responsabilidad penal, de quien recorre el camino del delito.

- A los ciudadanos, a quienes la norma penal trata de proteger y que representan el sustento principal de todo el ordenamiento jurídico, tomen en cuenta, que la ley penal pretende normar la vida organizada de la sociedad en que vivimos, no impidiendo que realicemos cualquier tipo de acciones, sino, previendo que ejecutemos acciones típicas de injustos penales que ofenden bienes jurídicos protegidos, y que crean inseguridad jurídica en otros miembros de la sociedad, de tal manera, que mas allá de la prohibición realizada por la norma penal sustantiva, hay un interés paterno de parte del Estado de prevenir, a través de la amenaza de la pena, conductas delictivas, con la finalidad de preservar la paz jurídica existente, o en el caso de que esta haya sido perturbada, el restablecerla en la medida de lo posible. 


\section{BIBLIOGRAFÍA}

- BACIGALUPO, Enrique, Lineamientos de la Teoría del Delito, Buenos Aires, Depalma 1974.

- CASTILlO GONZÁlEZ, Francisco, Tentativa Y Desistimiento Voluntario, San José, Costa Rica, Ed. Jurídico Continental, 2003.

- CÒDIGO PENAL DE LA REPÚBLICA DE NICARAGUA, Decreto No. 297 de 1 de abril de 1974, Publicado en La Gaceta No. 96 de 3 de mayo de 1974.

- COBO DEL ROSAL / M. VIVES ANTON, TS. Derecho Penal Parte General, Segunda Edición, Tirant lo blanch, Valencia, 1987.

- CONSTITUCIÓN POLÍTICA DE LA REPÚBLICA DE NICARAGUA, del año de 1987.

- CABANELlaS DE TORRES, Guillermo, Diccionario Jurídico Elemental, ed. Eliasta, Decimosexta edición, 2003.

- MIR PUIG, Santiago, Derecho Penal, Parte General, Sexta Edición -Barcelona 2002-

- MUÑOZ CONDE, Francisco / GARCÍA ARÁN, Mercedes, Derecho Penal Parte General, Editorial Valencia España, Tirant lo blanch, 1998.

- NUEVO CÒDIGO PENAL DE LA REPÚBLICA DE NICARAGUA, Ley No. 641, aprobada el 13 de noviembre 2007.

- QUIROS PIREZ, René, Manual de Derecho Penal, Editorial Félix Varela, San Miguel, El Mazón y Bassarrate, el Vedado, Ciudad de la Habana. 